\title{
El régimen de temporalidad en la historiografía mexicana del siglo XIX
}

\author{
The Temporality Regimen in Mexican \\ Historiography in the 19th Century \\ O regime de temporalidade na \\ historiografia mexicana do século xIX
}

Corina Yturbe ${ }^{1}$

Resumen

La relación que el historiador establece con el tiempo es un asunto fundamental. A partir de los conceptos metahistóricos de espacio de experiencia y horizonte de expectativa de Reinhart Koselleck, y de la noción de régimen de historicidad de François Hartog, que permiten interrogar las distintas experiencias del tiempo, es decir, las distintas maneras en que pasado, presente y futuro se articulan, se busca ver de qué manera estos conceptos pueden darnos un punto de vista más claro sobre el desarrollo de la historiografía en México durante el siglo xix. Se toma como ejemplo la Historia de México de Lucas Alamán, la cual representa el momento en que la historiografía entra en un distinto orden del tiempo, en un nuevo régimen de temporalidad. El tiempo histórico en el que Alamán escribe su Historia, engendrado por la tensión que existe entre el campo de la experiencia (el pasado colonial y la revolución independentista) y el horizonte de expectativa (la construcción de una nueva nación) muestra que la sociedad decimonónica experimenta su relación con el tiempo de una manera distinta, la que tendrá repercusiones sobre la manera de escribir la historia.

Palabras clave: Historiografía mexicana, espacio de experiencia, horizonte de expectativa, régimen de historicidad, Lucas Alamán

Abstract

The relationship that historians establish with time is a fundamental issue. This paper explores the way in which ideas about past, present and future articulate in the development of historiography in $19^{\text {th }}$-century Mexico. For that purpose, the paper explores the usefulness of Reinhart Koselleck's metahistorical concepts of space of experience and horizon of expectations, as well as François Hartog's notion of historicity regime. The example for this exploration is the Historia de México, by Lucas Alamán, which represents the moment in which historiography enters a different temporal order, i. e. a new "temporality regime". By the historical time in which Alamán writes, engendered by the tension between the space of experience--the colonial past- and the horizon of expectations - the building of a new nation-, the 19th-century society experiences its relationship with time in a different way, which will have repercussions on the way history is written.

Keywords: Mexican historiography, space of experience, horizon of expectations, historicity regime, Lucas Alamán

Resumo

A relação que o historiador estabelece com o tempo é um assunto fundamentaul. A partir dos conceitos meta-históricos do espaço de experiencia e do horizonte de expectativa de Reinhart Koselleck, e da noção de regime de historicidade de François Hartog, que permitem interrogar as diferentes experiências do tempo, ou seja, as diferentes maineras em que passado, presente e futuro são articulados, se-procura ver como é que esses conceitos podem dar um ponto de vista mais claro sobre o desenvolvimento da historiografia no Mexico durante o século XIX. Se põe como exemplo a História do México de Lucas Alamán, que representa o tempo em que a historiografia entra num ordem distinto do tempo, num novo regime de temporalidade. 0 tempo histórico no Alamán escreve sua História, gerado pela tensão entre o campo da experiência (o passado colonial e a Revolução da Independência) e o horizonte de expectativa (a construção de uma nova nação) mostra que o sociedade do século XIX com seu relacionamento experimenta o tempo de forma diferente, o que terá um impacto sobre a maneira de escrever a história.

Palavras Chave: Historiografía mexicana, espaço de experiencia, horizonte de expectativa, regime de historicidade, Lucas Alamán

Artículo recibido el 25 de noviembre de 2014 y aprobado el 27 de enero de 2016

1 Instituto de Investigaciones Filosóficas de la Universidad Nacional Autónoma de México (unam). Correo electrónico: corinayturbe@gmail.com 
Universidad Pedagógica Nacional

Facultad de Humanidades

El siglo XIx ha sido considerado como el siglo de la historia y de la revoluciones. Es el tiempo de la consolidación de la mayor parte de los Estados nacionales, en cuya construcción el discurso histórico fue uno de los medios más útiles y utilizados para lograr la unidad nacional de los nuevos países. Durante todo el siglo xix en Iberoamérica y en Europa, a través de la construcción de un pasado común, se pretendía crear una conciencia nacional que unificara e identificara a los nuevos ciudadanos. En México, mediante los relatos históricos de cronistas, maestros, historiadores, novelistas, artistas plásticos, el pasado era preservado, creado o recreado, interpretado o reinterpretado. Estas construcciones, escritos literarios, periodísticos o investigaciones y, en el caso de la historia, tratados con pretensiones de ser objetivos ("científicos") tenían como fin común inventar o recuperar el pasado y, aun si los modos y procedimientos de construirlo diferían dependiendo del enfoque ideológico, de la época, del ámbito, de los documentos disponibles, todos compartían la aspiración de hacer "historia". Si bien solo puede hablarse de la historia como actividad científica, como un saber autónomo productor de conocimientos sobre el pasado, desde finales del siglo XIx y, sobre todo, en el siglo xx después de la Revolución mexicana, el surgimiento de una nueva manera de entender las relaciones entre el pasado y el presente tiene su origen en el siglo XIx. En lo que sigue me centraré en la primera mitad del siglo XIX mexicano como uno de los momentos en los cuales los historiadores "inventaron" su pasado: intentaron construir un pasado nacional que todavía no existía, con el propósito de construir una nación ${ }^{2}$. Retomo el uso que hace François Hartog de las categorías metahistóricas espacio de experiencia y horizonte de expectativa de Reinhart Koselleck y su aplicación a las formas de escribir historia en la tradición francesa, trazando una ruta paralela con el siglo XIX mexicano con el fin de ver si se puede hablar de un nuevo régimen de historicidad, el cual permitiría

2 Como bien señala Chiaramonte (2004), en tiempos de las independencias americanas no existían las actuales naciones iberoamericanas, ni las correspondientes nacionalidades: estas no fueron el fundamento, sino fruto de esos movimientos (Véase Linares, 2012). sacar a la luz algunos aspectos de sus historiadores, de su manera de enfrentar la relación entre pasado, presente y futuro, así como del modo de escribir la historia. En la tensión que existía entre el espacio de experiencia y el horizonte de expectativa, trataré de mostrar, tomando como ejemplo a Lucas Alamán, de qué modo hay una nueva forma de articular pasado, presente y futuro, que dio lugar a una nueva forma de escribir la historia y sentó las bases de una concepción de la historia como un conocimiento científico del pasado.

\section{Temporalidad e historia}

El análisis del tiempo histórico y la concepción de la modernidad que está detrás de la filosofía de la historia de Reinhart Koselleck pueden entenderse a partir dos categorías fundamentales: el espacio de experiencia y el horizonte de expectativa3. En la antigua sensibilidad temporal, el espacio de experiencias resultaba empobrecido frente a un futuro no previsto, y esta distancia entre pasado y futuro ponía en crisis la percepción del tiempo, lo que daba lugar a una nueva experiencia del mismo, a una nueva articulación entre presente, pasado y futuro. Ya no era posible aplicar la experiencia pasada de manera inmediata a las novedades introducidas por los cambios que se producían cada vez con mayor rapidez, por lo que el futuro se volvía más impredecible y contingente.

"No existe ninguna historia que no haya sido constituida mediante las experiencias y esperanzas de personas que actúan o sufren" (Koselleck, 1993, p. 335), afirma Koselleck al introducir estas dos categorías metahistóricas, formales, como condición de posibilidad de las historias: espacio de experiencias y horizonte de expectativa, los cuales permiten relacionar a los actores con lo que, en otro lenguaje, se llama contexto. La experiencia es un pasado presente, cuyos acontecimientos han sido incorporados y recordados. La experiencia es el pasado hecho presente. En ella se fusionan tanto la elaboración racional como los modos inconscientes del comportamiento. Incluye

3 Seguiré la tesis de Koselleck según la cual la Revolución francesa fue un acontecimiento inaugural que instauró una nueva experiencia del tiempo. 
tanto la experiencia propia como la ajena transmitida a través de instituciones y generaciones. Reúne tanto la "experiencia vivida" o recordada, como el recuerdo de acontecimientos transmitidos. Las experiencias, en la medida en que pertenecen a la memoria, se modifican a lo largo del transcurso de la vida: las experiencias se acumulan en la memoria y se modifican respectivamente. Koselleck (1993) afirma: "Tiene sentido decir que la experiencia procedente del pasado es espacial, porque está reunida formando una totalidad en la que están simultáneamente presentes muchos estratos del tiempo anteriores, sin dar referencias de su antes ni su después" (p. 339). Las experiencias determinan el comportamiento presente y configuran así la posibilidad de un futuro: "Es el espacio de experiencia abierto hacia el futuro el que extiende el horizonte de expectativas" (p. 342). Así, la experiencia está unida a la expectativa.

Koselleck define el horizonte de expectativa como "aquella línea tras la cual se abre, en el futuro, un nuevo espacio de experiencia” (1993, p. 340). La expectativa hace referencia a un futuro anticipado, a lo que aún no es, a un futuro hecho presente: "Esperanza y miedo, deseo y voluntad, inquietud y análisis racional, visión receptiva y curiosidad, forman parte de la expectativa y la constituyen" (p. 339). Espacio de experiencias y horizonte de expectativas son condiciones de posibilidad de las historias, están presentes simultáneamente, pero no son conceptos simétricos, no hay una relación de espejo entre el pasado y el futuro. Lo que delimita el tiempo histórico es la tensión entre el espacio de experiencia y el horizonte de expectativa: "la tensión entre experiencia y expectativa es lo que provoca de manera cada vez diferente nuevas soluciones, empujando de ese modo desde sí misma al tiempo histórico” (p. 342). El tiempo histórico (la temporalidad de la historia) está determinado por la relación inestable entre el espacio de experiencia y el horizonte de expectativa: "la experiencia y la expectativa son dos categorías adecuadas para tematizar el tiempo histórico por entrecruzar el pasado y el futuro" (p. 337). Así, a partir de la asimetría entre estos dos conceptos y de las diferencias históricas en la forma de coordinación entre ambos, Koselleck concibe la modernidad como "[...] un tiempo nuevo en el que las expectativas se han ido alejando cada vez más de las experiencias hechas" (p. 343).

Posteriormente, François Hartog (2003) introduce la idea de "régimen de historicidad" para referirse a las diferentes formas de articular pasado, presente y futuro, regímenes que surgen de períodos más o menos prolongados de "crisis del tiempo", es decir, esos momentos (brechas en el tiempo) en los que el pasado, el presente y el futuro se articulan de una manera distinta: "intervalos enteramente determinados por cosas que ya no son y por cosas que todavía no son" (Hartog, 2003, p. 118). Esta idea permite comprender las nuevas maneras de experimentar la temporalidad en la modernidad, superando el antiguo "régimen de historicidad", en el cual el pasado rige la relación entre el presente y el futuro, donde domina el modelo de la "historia como maestra de vida". Mientras que la relación de las categorías de Koselleck, "espacio de experiencia" y "horizonte de expectativa" es la condición de posibilidad de toda historia, el "régimen de historicidad" de Hartog registra las articulaciones entre pasado, presente y futuro.

En la medida en que los diferentes regímenes de historicidad se pueden relacionar con diferentes formas de historiografía, el paso de un régimen de temporalidad a otro implicó un cambio en las formas de pensar y de escribir la historia:

Con el régimen de historicidad se llega así a una de las condiciones de posibilidad de la producción de historias: según las relaciones respectivas del presente, del pasado y del futuro, son posibles ciertos tipos de historia y otros no (Hartog, 2003, p. 28).

Si bien el pasado sigue teniendo de alguna manera un carácter ejemplar o normativo para el presente, este modelo de la historia como "maestra de la vida" se va modificando poco a poco, y da lugar a que el historiador instaure una nueva relación con su tiempo: las lecciones ya no vienen del pasado, sino del futuro. Para Alamán, el pasado son los tres siglos de colonia y el medio siglo de los intentos por instaurar el régimen republicano después de la Independencia en México, años de disrupción, 
Universidad Pedagógica Nacional

Facultad de Humanidades

violencia y desorden. Ya no se estudia el pasado como si fuera algo dado, sino que se ensayan otras formas, supuestamente más objetivas, más "científicas", para establecer conexiones con el presente. El trabajo del historiador, en este sentido, es el de reconstruir el pasado para construir el presente e inventar un nuevo futuro, sobre la base de una ruptura entre pasado y presente.

Para mostrar cómo se traducen las experiencias del tiempo en las narraciones históricas, Hartog retoma las reflexiones de tres pensadores: Volney, Chateaubriand y Tocqueville, y revela de qué manera fueron testigos de un cuestionamiento profundo del orden del tiempo. Cada uno de ellos supo que el antiguo régimen, el régimen prerrevolucionario, había llegado a su fin, que ya no era posible seguir pensando que el pasado alumbra el futuro. El Ensayo histórico sobre las revoluciones de Chateaubriand y Las ruinas o meditaciones sobre las revoluciones de los imperios de Volney se elaboran entre dos regímenes de historicidad, en un momento de crisis: "El antiguo régimen de historicidad, que era precisamente ese tiempo en el que el pasado aclaraba el futuro, está definitivamente terminado. [...] la inteligibilidad de lo que venía implicaba articular de otra manera las categorías de pasado y futuro [...]" (Hartog, 2003, pp. 107-111). El horizonte de experiencia de Chateaubriand es la visión de una América primitiva que en poco tiempo supo inventar la libertad moderna: se convirtió en el recipiente donde se forjó (se inventó) el futuro. Posteriormente Tocqueville afirmó

Aunque la revolución que se lleva a cabo en el Estado social, las leyes, las ideas, los sentimientos de los hombres, estén muy lejos de haber terminado, no se podrían comparar sus obras con nada de lo que se ha visto anteriormente en el mundo. Remonto de siglo en siglo hasta la Antigüedad más lejana: no percibo nada que se parezca a lo que tengo bajo mis ojos. En tanto que el pasado ya no ilumina el futuro, el espíritu camina en tinieblas. (Tocqueville, citado por Hartog, 2003, p. 113)

Es decir, la luz viene de un futuro que ya está ahí en Estados Unidos, el mundo nuevo de la igualdad, hacia el cual Europa camina lenta y dificultosamente: "De una orilla a otra del Atlántico se abrió una distancia entre la experiencia y la espera" (Hartog, 2003, p. 111). En el caso de Alamán, había que inventar un futuro: hacer de México una verdadera nación con una forma de gobierno estable, con una autoridad efectiva que fuera capaz de sustituir las estructuras del viejo Estado.

La práctica de la historiografía se concibe desde entonces como un saber con respecto del pasado, y este conocimiento sirve para explicar el presente y proponer expectativas para el futuro ${ }^{4}$. En la historiografía mexicana, la clave con la que se reconstruye el pasado y se explica el presente es una clave nacional: desde la Independencia se va construyendo un imaginario nacional; poco a poco, los relatos nacionales se convierten en la "historia oficial" de México, y abren la posibilidad de forjar una nación de la que todos los mexicanos puedan sentirse miembros.

En la formación de la identidad nacional se recurre a la historia, extrayendo de ella acontecimientos, ejemplos, fechas emblemáticas. Se pretende que a partir de esta "historia", los individuos adquieran un sentido de pertenencia a la sociedad y por extensión al Estado-nación. Cada uno de ellos proyecta su existencia individual en la trama de esa narración colectiva, en el reconocimiento de un nombre común, y sobre tradiciones vividas como la huella de un pasado remoto. Al igual que la "historia nacional" que produce una visión más o menos uniforme de los procesos históricos y sociales, estas tradiciones las más de las veces son fabricadas e inculcadas, y es a partir de ellas que se "inventa" una nación, incluso donde no existe. Hobsbawm señala que en términos de la invención de la tradición hay tres innovaciones particularmente relevantes: el desarrollo de la educación primaria, como el equivalente secular de la Iglesia, la invención de las ceremonias públicas y la producción masiva de monumentos públicos (Hobsbawm, E. J., 1994, pp. 77-78).

4 Para un análisis de la manera en que se realizó el proceso de sustitución de una forma de escritura de la historia por otra véase Zermeño 2003, pp. 49-83. 
La crisis del antiguo "régimen de historicidad" estimula a la historia a ir abandonando la retórica clásica, y sustituir sus procedimientos con una escritura en la que los historiadores traducen y ordenan las experiencias del tiempo y les dan sentido de una manera distinta

Con el advenimiento de la modernidad, este cambio de temporalidad es más o menos semejante en Europa y en Hispanoamérica. Si volvemos la mirada hacia Europa, Francia en particular, después de la Revolución francesa la historiografía entra en una especie de impasse: no hay nada nuevo, dicen Rosanvallon (1985) y Lefebvre (1974) entre otros: se habla de "la ausencia de la historia". Sin embargo, a partir de las primeras décadas del siglo XIX, los hombres de ese momento se imponen como tarea la construcción de una nueva Francia, ya que la antigua había sido destruida por sus predecesores de 1789 (Rosanvallon, 1985, p. 18). La historia demostró ser una de las herramientas más efectivas en esa empresa.

La época de los historiadores del siglo XIX conoció el triunfo de la Revolución de 1789, consagrada por la Carta de 1814 y la Revolución de 1830, liberal y nacional, que logró la autonomía de la nación y el triunfo de las ideas de 1789. Los historiadores de esta época son periodistas y hombres políticos: François Guizot, Augustin Thierry, Adolphe Thiers, François Mignet. Se trata de historiadores liberales, ligados al siglo XviII: "Entran en la historia, conscientemente o no, para defender su causa [...]. Se trata de una historia pragmática que proporciona argumentos a la vez que una lección. Todo ello les inclina a una cierta indulgencia hacia las revoluciones" (Lefebvre, 1974, p. 171). Estos historiadores "liberales" franceses se resisten a llevar hasta sus últimas consecuencias el programa de la Revolución de 1789, y centran su reflexión en los problemas políticos engendrados por la transformación revolucionaria que dio lugar a la destrucción del orden absolutista. Alamán, por su parte, tiene una ruta paralela a la de los llamados

5 “Los revolucionarios apenas se interesaban por la historia: tenían otras tareas. [...] Sin embargo, bajo el Imperio y durante los primeros años de la Restauración, la historia recobró poco a poco el favor del público" (Lefebvre, 1974, p. 165). "doctrinarios"6, movimiento que en México tiene su origen en el desvío de un grupo de liberales hacia posiciones conservadoras como reacción a la radicalización del movimiento liberal. Tiene en común con ellos la oposición a un liberalismo demoledor, la crítica a la revolución, en la que según ellos no había habido más que horror y crimen. Sin embargo, igual que ellos, si bien es antirrevolucionario no es reaccionario: la tarea que se proponen es construir un nuevo México, una vez que el México antiguo fue destruido por las guerras de Independencia ${ }^{7}$. Después de seguir los fracasos y contradicciones de los intentos liberales por conseguir un Estado fuerte y duradero, Alamán se va moviendo hacia posiciones cada vez más conservadoras, y encuentra mayor afinidad con las ideas de Edmund Burke.

De manera similar, cuando se habla de "historiadores" del siglo XIX mexicano, no se diferencia entre historiadores y políticos. La mayoría de ellos eran hombres "prácticos", predominantemente funcionarios de Estado (de un Estado en construcción), muchos otros dedicados al periodismo político y, a medida que avanzaba el siglo, los que se consideraban "hombres de letras" se unieron a la tarea de la recuperación del pasado. Durante la primera parte del siglo, las obras históricas mexicanas se ocuparon fundamentalmente del pasado más inmediato: el interés de estos historiadores era dar cuenta de las guerras de emancipación. Casi todos ellos fueron actores en dichos procesos, por lo que sus escritos fueron una forma más de hacer política ${ }^{8}$, cuyo principal problema era explicar por qué el país en ningún momento desde su independencia había logrado constituirse políticamente y proponer algún tipo de organización del Estado. En sus preocupaciones había un claro predominio de lo político sobre

6 El origen de los doctrinarios en el mundo hispánico se encuentra en el repliegue de un sector de los liberales mexicanos hacia posiciones más conservadoras como reacción a la radicalización del movimiento liberal (cf. Cano, Suárez Cortina y Trejo Estrada (eds.), 2010).

7 En su estudio sobre Guizot, Rosanvallon (1985) analiza los problemas planteados por la evolución del pensamiento moderno en una sociedad del Antiguo Régimen.

8 “Como documento, su discurso vale no sólo por lo que dice, sino por lo que pretende hacer: proponer, convocar, descalificar, convencer" (Pani, 2009, p. 16). 
Universidad Pedagógica Nacional

Facultad de Humanidades

cuestiones de otro tipo, como las religiosas (que con frecuencia no eran fáciles de distinguir de las propiamente políticas) y otros aspectos de la vida social, ya que de lo que se trataba era de esclarecer los hechos para impugnar a sus rivales y justificar sus actos.

A partir de la Independencia, fueron muchos los autores que se ocuparon de hacer historia, desde distintas perspectivas, sobre el proceso de emancipación y sobre las características que debería tener el nuevo Estado. Podemos mencionar algunos nombres $^{9}$ de quienes elaboraron distintos proyectos para consolidar la nación y definir los principios políticos de la nueva sociedad, los cuales fueron creados en el terreno de la reflexión histórica: Servando Teresa de Mier (1813-) (1986); Carlos María de Bustamante (1842-1844) (1985); Lorenzo de Zavala (1808-1830) (1985); José María Luis Mora (1836) (1965).

\section{Religión e Iglesia: el conflicto entre liberales y conservadores}

El conflicto entre liberales y conservadores marcó la vida política de México durante la primera mitad del siglo XIX. Asimismo, dejó profundas huellas en el desarrollo de la historiografía, en la que los distintos actores defendieron sus posiciones en el momento de imaginar, o inventar, el rostro que tenía y debía adquirir la nueva nación. Las ideas, opiniones y declaraciones políticas sobre cuál debería ser la organización política del país (la defensa del régimen colonial o su oposición) causaron tensiones y conflictos ideológicos que dieron lugar a una división en dos grandes grupos políticos: liberales y conservadores ${ }^{10}$. "De la oposición y choque de esas

9 Fueron muchos más los que de alguna manera prepararon el terreno para la Historia de México de Lucas Alamán: Vicente Rocafuerte, Mariano Otero, Joel Roberts Poinsett. (Véase Ortega y Medina, y Camelo, 2011, vol. III).

10 Resulta imposible dar una definición exacta del liberalismo y del conservadurismo: no sólo porque tomaron diversas formas, sino porque como conceptos ideológicos (de movimiento, dirá Koselleck) son indefinibles: como conceptos son abiertos, polisémicos y equívocos. Siguiendo a Koselleck, no se les puede tratar como entidades puramente abstractas, al margen de las intenciones de los agentes, de los contextos intelectuales y de los cambios históricos, a partir de los cuales adquieren una pluralidad de significaciones articuladas históricamente. Aquí tomaré solo dos tendencias - señala Edmundo O'Gormansurgió el conflicto liberal-conservador que, por sus implicaciones y relevancia, debe estimarse como el suceso-eje del acontecer nacional" (1999, p. 31). Sin embargo, esta lucha entre contrarios que buscaban algo muy parecido (construir la nueva nación), a pesar de que hubiera una diferencia básica en sus respectivas premisas, tanto en su política como en su forma de pensar y de escribir historia, como progresismo ilustrado y providencialismo católico, no era la disyuntiva entre dos posibilidades, "sino la disyuntiva entre dos imposibilidades". Es, según O’Gorman (1999, p. 41), "la encrucijada de Jano": una incompatibilidad entre pasado y futuro ${ }^{11}$. Lucas Alamán disentía del pensamiento de la Ilustración, y era reacio a la idea de progreso, cuando éste se llevaba a cabo a través de medios violentos. Era providencialista, pero esta perspectiva le permitió pensar en un futuro diferente. En realidad, la alternativa está más bien en la valoración de la experiencia pasada: la pregunta era si construir sobre ella o innovar radicalmente, abriendo en ambos casos un nuevo horizonte de expectativa.

Al hablar de la diferencia entre el liberalismo y el conservadurismo, habría que evitar la idea según la cual los liberales, con la mirada puesta en el progreso, repudiaban lo tradicional y buscaban establecer un nuevo orden mediante reformas más o menos radicales. Los conservadores, por su parte, rechazaban la revolución, eran enemigos de los cambios políticos y en lo social defendían los valores de la familia tradicional y de la Iglesia católica, aspiraban a conservar y a justificar lo tradicional como un orden válido. Eran defensores de la ley y el orden y del principio de autoridad (Noriega, 1972, p. 274). En realidad, conservadores y liberales coincidían en sus propuestas políticas y sociales ${ }^{12}$ :

algunos de los rasgos fundamentales de cada una de estas posiciones políticas con el fin de ubicar el pensamiento político y la concepción de la historia de Lucas Alamán.

11 Según 0' Gorman, la tendencia conservadora no es capaz de reconocer las exigencias de un futuro "alucinante", y la tendencia liberal no es capaz de reconocer las exigencias de un pasado venerable y venerado (1999, p. 40)

12 Como lo señalan Fowler y Morales, el liberalismo y el conservadurismo del siglo XIX no eran tan drásticamente diferentes en los 
buscaron en su mayoría el progreso, la modernidad y el bienestar de la nueva nación. Ambos querían forjar una nación. Si bien no había ningún interés en conservar el sistema político colonial, sí existía una tendencia a considerar que no había que desmantelar totalmente o, en todo caso, de manera drástica, la herencia española, la cual formaba parte de la nueva identidad nacional.

Los primeros liberales buscaban implantar un proyecto de nación "moderna", una nación de iguales, autónoma y soberana, integrada por ciudadanos libres ${ }^{13}$. Su objetivo primordial después de la Independencia, y que perdurará quizás hasta nuestros días, era el de construir un sistema político que crearía prosperidad, orden, estabilidad y progreso, mediante una constitución. Fue una época en la que, como afirma Charles Hale, dominó "la fe en la magia de las constituciones" (2005, p. 81):

\section{[...] el meollo del liberalismo político mexicano} durante la primera década de la independencia fue la formación de un sistema constitucional, cuyos elementos serían una separación de poderes efectiva, una ambivalencia - si no es que abierta hostilidad - hacia la soberanía popular y un vínculo entre los derechos individuales y los intereses de propietarios como la garantía de estabilidad. (2008, pp. 5-6)

La diferencia más profunda entre estos dos grupos se centró en la problemática producida por la tensión entre religión y laicismo. Un hecho que está en el origen de esta tensión es que en México como parte de la monarquía hispánica, al igual que España, tiene una población mayoritariamente católica y la Iglesia como institución tiene un peso enorme:

fines que perseguían. Es más, “el pensamiento conservador surgió dentro del movimiento liberal y no a su lado" (Morales \& Fowler, 1999, pp. 11-12). En el mismo sentido, Hale sostiene: “En muchas formas, los liberales y los conservadores no siempre estuvieron tan alejados. Compartían muchos supuestos comunes, especialmente en los problemas sociales" (Hale, 2005, p. 12).

13 Con la adopción de las ideas liberales, la concepción de nación "cultural" se modifica para ser suplantada (o para incluir) la concepción de nación política (véase, Linares, 2012).
Esa tradición, la inserción en lo que genéricamente se denomina cultura latina, aquella que predomina en el sur de Europa y América hispana, se ha caracterizado por el agudo conflicto entre la Iglesia católica y el Estado liberal, mostrando un modelo de modernidad conflictiva alejado de aquel otro que se desarrolló en los países de tradición protestante, donde el proceso secularizador desde el interior de las religiones atenuó el conflicto entre la Iglesia y el Estado. (Suárez, 2013, p. 39)

El proyecto económico de los liberales tenía una intención claramente política; pero, más allá de la desamortización de los bienes de la Iglesia con el fin de saldar la deuda externa y de sostener la guerra contra las invasiones primero de Estados Unidos y despúes de Francia, su proyecto cultural a largo plazo era, fundamentalmente, la secularización de la sociedad. Sin embargo, se preguntaban si, en una sociedad conformada por el catolicismo, iban a ser capaces de sustituir la unidad religiosa que, hasta ese momento, era la base de la unidad nacional, por lo que sus ataques estuvieron más bien dirigidos a la Iglesia católica. En las primeras décadas después de la Independencia la cuestión religiosa no constituyó un elemento de tensión; sus primeros proyectos muestran al catolicismo como la religión indiscutible del nuevo Estado ${ }^{14}$. Pero si pretendían construir un nuevo país, las grandes porciones de tierras en manos de la Iglesia y los privilegios corporativistas de los grupos indígenas heredados del derecho colonial que los protegían, representaban un freno a la modernización económica de la nación. Estaban convencidos de que los privilegios económicos y político-jurídicos de la Iglesia católica frenaban el desarrollo y la implantación de la doctrina liberal. De ahí que intentaran romper el bloque hegemónico de los conservadores con la Iglesia católica, incapaz de reformarse, de abandonar sus privilegios y encontrar valores propios. En las primeras décadas después de la Independencia la cuestión religiosa no constituyó un elemento de tensión; sus primeros proyectos muestran al catolicismo como la religión

14 Es el caso de la constitución de Apatzingán, del Plan de Iguala, de la Constitución de 1824 
Universidad Pedagógica Nacional

Facultad de Humanidades

indiscutible del nuevo Estado ${ }^{15}$. Sin embargo, la Iglesia en México mantuvo su posición privilegiada, frenando los proyectos de reforma liberal, en cuya defensa los conservadores tuvieron un papel fundamental al poner en un lugar central de su visión de la sociedad a la religión católica y a la Iglesia. La tensión entre los liberales y la Iglesia, apoyada siempre por los conservadores - para quienes la peor desgracia de México sería el abandono de la tradición hispánica sustentada en la religión y en la monarquía - se concretó en un principio en la lucha contra el artículo 3 de la Constitución de 1824, que establecía la protección oficial de la Iglesia, y contra el artículo 154, que perpetuaba los privilegios del clero y de los militares. El liberal más representativo de su generación, José María Luis Mora, define la marcha política del progreso como el programa anticlerical de Gómez Farías: desamortización de los bienes de manos muertas, abolición de los fueros y difusión de la escuela laica ${ }^{16}$.

En general, los conservadores concebían a la Iglesia como central para la estabilidad de la sociedad, así como para la autoridad del Estado, si bien los modos como veían sus lazos políticos con esa institución variaban. Algunos parecían pensar en la Iglesia y en la religión católica de modo instrumental, como una institución y un culto que eran útiles como un vínculo social de cohesión, o como un medio para la movilización política. Esta tendencia a utilizar la religión como fuente de apoyo político, o como arma política, condujo a los conservadores a colocar a la Iglesia en el centro de las controversias políticas y a los liberales a intentar reducir los poderes y privilegios eclesiásticos. La religión católica era la base de la sociedad, así que la libertad y el orden solo podían subsistir apoyados por los preceptos

15 El artículo 4. ${ }^{\circ}$ de la Constitución de 1824 afirma que “la religión de la nación Mexicana es y será perpetuamente la católica, apostólica, romana".

16 No será sino hasta el Plan de Ayutla, la Constitución de 1857 y las Leyes de Reforma cuando los liberales logran la separación entre la Iglesia y el Estado, iniciando un período de confrontación entre las esferas civil y religiosa. Estas tensiones provocaron además el desarrollo de movimientos anticlericales que constituyeron la respuesta de los sectores liberales más radicales frente al poder de la Iglesia. de la fe católica. En la famosa "Carta de don Lucas Alamán a Santa Anna”, Alamán señala

[...] cuáles son los principios que profesan los conservadores, y que sigue por impulso general toda la gente de bien. Es el primero en conservar la religión católica, porque creemos en ella, y porque aun cuando no la tuviésemos por divina, la consideramos como el único lazo común que liga a todos los mejicanos, cuando todos los demás han sido rotos, y como lo único capaz de sostener a la raza hispanoamericana, y que puede librarla de los grandes peligros a que está expuesta. (1997 [1853], pp. 351-352).

Una de las cuestiones que más oposición suscitó entre los sectores conservadores fue la libertad de cultos, que representaba un temor a perder ese sentido de identidad en el momento en que se estaba forjando. La religión y sus instituciones seguían gobernando toda la vida pública y privada de la sociedad. La recomposición del universo humano y social, en la que otras esferas del saber fueron ocupando el lugar de la religión, pasando de lo sagrado a lo secular, se dio de manera paulatina y conflictiva, debido al poder de la Iglesia y, sobre todo, al arraigo del catolicismo en la sociedad.

Alamán era íntegramente católico. Su profundo sentido religioso - "graníticamente ortodoxo" (Noriega 1972, p. 71)—, lo lleva a ver en el cristianismo la única posibilidad de liberar al hombre de la superstición y la barbarie, y en la Providencia divina la mano que salvaría a México de la catástrofe en que se hallaba. Todos los hechos de la historia responden a los designios de la voluntad divina (Mijangos, 2004, pp. 56-57). Alamán presenta la Conquista como un acontecimiento providencial por el cual se pudo establecer la Iglesia y difundir la civilización cristiana; en México: “[...] religión, lengua, costumbres, leyes, habitantes, todo es resultado de la conquista y en ella no deben examinarse los males pasajeros que causó, sino los efectos permanentes mientras exista esta nación" (1942, t. 1, p. 120). Veía en la Iglesia el único elemento que le daba unidad a la sociedad mexicana después de la Independencia. Al hacer el recuento de medio siglo de la historia de México, consideraba que: "En medio de un 
trastorno tan completo de todos los elementos de la sociedad, lo único que ha permanecido inmutable es la iglesia [...]” (1985, p. 906). Para sacar al país de la catástrofe era necesario mantener la unidad en torno a la raíz católica de la nación. Cuando en 1848 fundó el partido conservador, su primer principio fue conservar la religión Católica.

\section{Presente, pasado y futuro}

En el intento de ofrecerle a la nueva nación un pasado que permitiera entender el presente y proponer expectativas de futuro, hubo $-\mathrm{y}$ hay $-{ }^{17}$ largas $\mathrm{y}$ acaloradas disputas sobre las creencias acerca de lo que se considera como el pasado sobre el que podría fundarse la nueva nación. De ahí que los contenidos de la historiografía estuvieran siempre sujetos a reajustes y contrastes, lo que dio lugar a interpretaciones divergentes o incluso contradictorias de la historia. Por un lado, el proceso político mexicano del siglo XIX ha sido interpretado como una constante lucha liberal y democrática en contra de las fuerzas de la opresión política y del clero, la injusticia social y la explotación económica. Esta interpretación liberal es la que ha predominado en la historiografía mexicana. Por otro lado, los conservadores interpretaron ese proceso liberal como una sucesión de esfuerzos por destruir las tradiciones hispánicas, por implantar ideas y valores extranjeros y como consecuencia de esto, condenar al país a la anarquía y a la corrupción. Sin embargo, en el centro de cada una existió un interés por forjar una nación. Tanto liberales como conservadores intentaron construir una imagen de una nación a partir de la invocación del pasado o, más bien, a partir de la invención de un pasado, que pudiera hacer compatibles una sociedad tradicional con raíces españolas, con una sociedad con cara

17 Valdría la pena comparar esas disputas con las que se dieron en la construcción de una nueva historia de México con motivo del Bicentenario. Para una muestra del uso político de la historia, véase el libro de historia de México presentado por el presidente Felipe Calderón en el que varios historiadores se ocupan de los temas más importantes de nuestra historia. Tal vez no debería sorprendernos que casi la mitad del libro esté dedicada al análisis de la Conquista y el Virreinato: von Wobeser, Gisela (coord) (2010), Historia de México, México: Presidencia de la República-SEP- FCE- Academia Mexicana de Historia. hacia el futuro, y en cuya historia el lugar del mundo indígena era incierto.

La tendencia política conservadora está ya presente desde la Independencia: para estos "conservadores avant la lettre el ideal era el régimen español anterior a la Independencia, pero sin España, ellos mismos dirigiendo el gobierno y ocupando los cargos que anteriormente tenían los Peninsulares" (Chevalier, 1999, p. 3). Para los conservadores, el movimiento iniciado por Hidalgo y Morelos se había caracterizado por la violencia y la anarquía. Iturbide, en cambio, era un verdadero héroe porque, además de conducir el proceso de independencia y darle vigencia, lo había hecho sin violencia, tratando de no romper radicalmente ninguna estructura fundamental. Consideraban que la realidad en todos sus aspectos (socio-económico, político, ideológico, religioso) era algo dado y constituido en un pasado remoto por obra divina, que debía mantenerse inmutable o con el menor cambio posible. Percibían como amenaza los cambios que representaban un riesgo para sus intereses y sus viejos privilegios. Su proyecto de nación buscaba instaurar un orden social basado en el fortalecimiento de las instituciones tradicionales encargadas de vigilar el orden moral, opuesto a la persecución de las libertades individuales difundidas por los liberales, a la pérdida de privilegios de la Iglesia promovidos por el jacobinismo, y a las ideas racionalistas que debilitan el poder cultural y moral de las instituciones tradicionales: la familia, la parroquia, la comunidad ( $c f$. Kirk, 1953).

Al igual que los liberales, los conservadores tenían un gran interés en el desarrollo nacional, pero diferían en el modo de lograrlo. Si bien rechazaban el lema del "progreso" de los liberales, proponiendo en su lugar el "orden", sus defensores mostraron ser mucho más pragmáticos políticamente y modernos económicamente que los liberales, en tanto que sus expectativas de futuro en cuanto al gobierno que le convenía a la república y su mejor comprensión de la realidad económica estaban más de acuerdo con la realidad de la nueva nación. Las propuestas políticas que formularon buscaron el progreso mediante un 
Universidad Pedagógica Nacional

Facultad de Humanidades

proceso de industrialización financiado por capital extranjero, para lo cual se requería proyectar una imagen de orden y estabilidad.

Lucas Alamán, apoyándose en la historia (en el espacio de experiencias después de la derrota en la guerra contra la invasión norteamericana) y siguiendo de cerca las tesis del defensor de la constitución inglesa Edmund Burke en el periódico El Universal. Periódico Independiente, precisaba el sentido del nuevo partido:

Nosotros nos llamamos conservadores. ¿Sabéis por qué? Porque queremos primero conservar la débil vida que queda de esta pobre sociedad, a quien habéis herido de muerte; y después de restituirle el vigor y lozanía que puede y debe tener, que vosotros arrebatasteis y que nosotros le devolveremos [...] somos conservadores porque no queremos que siga adelante el despojo que hicisteis: despojasteis a la patria de su nacionalidad, de sus virtudes, de sus riquezas, de su valor, de su fuerza, de sus esperanzas [...] el partido conservador no ha promovido ninguna revolución [...] los hombres del partido conservador han figurado algunas veces en la administración pública, $y$ han ejercido su influencia en los negocios; pero influir no quiere decir dominar. (Citado por González Navarro, 1952, pp. 127-128)

Es un error pensar en los conservadores como católicos fanáticos, egoístas, que trataron de impedir la venta de las tierras de la Iglesia para impedir el desarrollo capitalista. Si su crítica resulta corrosiva e insólita es por su cuestionamiento del orden de las cosas: "no pretendía condenar la corrupción o el mal funcionamiento de un sistema, sino minar los cimientos mismos del orden posrevolucionario, exponiendo la irracionalidad de sus supuestos, de las ficciones que lo hacían viable" (Pani, 2009, p. 15). Las políticas pragmáticas de los conservadores revelaban una mejor comprensión de las realidades económicas del país y promovían una primera industrialización moderna: "lo que es esencial para cualquier definición del conservadurismo mexicano de los años cuarenta es que acentuó sobre todo la importancia del pragmatismo" (Morales \& Fowler, 1999 , p. 17). Este pragmatismo de los conservadores subrayaba la importancia del pasado, por lo que el progreso surgiría gradualmente a través de reformas que respetaran la realidad pasada y presente.

En el editorial del primer número del periódico conservador El Tiempo, publicado en enero de 1846 y probablemente escrito por Alamán, se resume el razonamiento de los conservadores. Contra el racionalismo de los principios abstractos, argumenta a favor de la experiencia:

Hízose pues, una constitución sobre una base imaginaria y todas las revueltas, todas las conmociones que desde entonces se han sucedido una a otra, no han sido otra cosa que el choque necesario entre los elementos ficticios de la Constitución, y los elementos que realmente componen nuestra sociedad política [...]. (citado por Noriega, 1972, p. 352)

Años después, el historiador y político mexicano José María Tornel coincidió con estas ideas y señaló que el problema radicaba en que "sin preparar antes el campo, hemos sembrado plantas exóticas que murieron al nacer" (Tornel y Mendivil, 1985 [1852], p. 14).

\section{Lucas Alamán: el historiador}

Lucas Alamán (1792-1853) fue un historiador y un político activo que se dio a la tarea de explicar su presente para así abordar su futuro ${ }^{18}$. De ideología política conservadora, identificó a la nación mexicana con la herencia española y llegó a respaldar ideas monárquicas como posible solución al desorden político y social. Dadas las circunstancias del país, la monarquía se presentaba como una opción pragmática y factible que permitiría enfrentar la

18 Ocupó varios cargos políticos a lo largo de su vida: diputado a las Cortes de Cádiz, ministro de Relaciones en los gobiernos de Bravo y en el de Anastasio Bustamante; director de la Junta de Industria y ministro de Relaciones Exteriores durante el último gobierno de Santa Anna; presidente del Ayuntamiento de México; organizador del Banco del Avío, para fomentar la industria, la agricultura y la ganadería; impulsor de la instauración de una industria nacional mediante la creación de varias empresas (compañías mineras, fábricas de hilados y tejidos); director del periódico El Tiempo, fundador del Partido Conservador y de su órgano de difusión, El Universal; preocupado por el estudio del pasado, organizó el Archivo General de la Nación. 
necesidad de mantener un cierto orden social y, al mismo tiempo, conservar la religión católica y la herencia española ${ }^{19}$.

Alamán defendió sus creencias desde los diferentes puestos públicos que ocupó, así como en su obra escrita, desde las Disertaciones sobre la historia de la República Mexicana desde la época de la conquista que los españoles hicieron a fines del siglo $x \mathrm{~V} y$ principios del XVI de la islas y continente americano hasta la Independencia (1844-1849), donde aborda la Conquista y la dominación española, hasta su Historia de Méjico desde los primeros movimientos que prepararon la Independencia en el año 1808 hasta la época presente (1849-1852), en la que escribe sobre el campo que más le interesaba: la historia contemporánea de la guerra de Independencia, de Hidalgo a Iturbide, hasta llegar a la época de su escritura.

Según Alamán el propósito de sus escritos de historia era combatir la falta de respeto popular por la herencia española de México y la idea de que la Independencia constituía un rompimiento necesario con ella. Buscó dejar constancia de que el trágico presente de su patria y el futuro tan ominoso al que se enfrentaba se debían a ese pasado inmediato que había equivocado el curso seguido hasta entonces por la historia.

En su obsesión por encontrar los orígenes de la historia de México, hilo conductor de toda su obra historiográfica, escogería como raíz de lo mexicano a lo español. En las Disertaciones se plantea como problema central el de la validez de la Conquista:

[...] estas revoluciones que mudan la faz del orbe y que tienen el nombre de conquistas no deben ser consideradas ni en razón de la justicia ni de los medios que se emplean para su ejecución,

19 Como señala Pérez Vejo, “El monarquismo mexicano de los años cuarenta-cincuenta está teñido de un fuerte componente utilitario. La justificación de la monarquía nunca se hace con base en una supuesta legitimidad [...], sino argumentando la capacidad de este sistema de gobierno para garantizar una transición ordenada del antiguo régimen a la nueva sociedad nacional y de garantizar el carácter católico y español de México frente a la amenaza anglosajona" (Landavazo \& Sánchez, 2008, p. 329). En este sentido, cuando Alamán apoya al imperio de Iturbide, lo hace porque en ese momento esa propuesta era la que permitiría regresar al orden. sino más bien en razón de sus consecuencias.

(González Navarro, 1985, p. XIII)

Con una sólida base documental, deja claramente establecido que el inicio de la historia del país no es 1810, como afirmaba Bustamante, sino su conquista por los españoles, y que Hernán Cortés había sido el fundador de la nación mexicana. Los tres siglos de régimen colonial habían sido benéficos y progresistas: el único camino para la salvación de México era rechazar las doctrinas liberales y regresar a las prácticas aprobadas por el tiempo. Cuestionaba permanentemente la validez de los supuestos principios universales instituidos a partir de la Independencia pues consideraba, siguiendo a Burke, que la Constitución de una nación estaba en sus costumbres e instituciones, heredadas por generaciones.

$\mathrm{Su}$ Historia de México desde los primeros movimientos que prepararon su Independencia en el año de 1808 hasta la época presente, escrita entre 1849 y 1852 , es una magna obra de revisión histórica ${ }^{20}$, en la que trata de mostrar el camino equivocado que había tomado México a raíz de su independencia y plantear propuestas para la regeneración del país. La búsqueda de la verdad en los hechos lo conduce a evaluar los méritos y los errores de los actores individuales y colectivos, y a considerar sus respectivas causas. Así como en las Disertaciones justificaba la Conquista, en su Historia, lamenta la Independencia, aun cuando su posición no es negativa de manera tajante, ya que la considera como inevitable. No obstante, deplora el hecho de que la nueva nación no haya podido conservar el orden y los valores de la época colonial. Muestra su pesimismo por el fracaso de proyectos, constituciones, gobiernos y reformas sin que ninguno llegara a funcionar. $\mathrm{Su}$ preocupación, dice, era la República en la que estaba comprometido y creía tener la obligación de darle

20 Cuando Alamán habla de "revisión histórica" se refiere sobre todo a la obra de Carlos María de Bustamante, Cuadro histórico de la Revolución Mexicana de 1810, 8 vols., obra que critica por considerar que su autor estaba más interesado en la difusión de la historia que en el análisis riguroso y desapasionado de los hechos históricos. Con todo, Alamán utilizó la enorme cantidad de documentos y noticias reunidas (sin orden ni método) por Bustamante, tomándose el cuidado de cotejar cada documento. 
Universidad Pedagógica Nacional

Facultad de Humanidades

un trasfondo histórico que esclareciera el presente y el futuro. A lo largo de los cinco volúmenes Alamán lleva a cabo un seguimiento cronológico y a la vez temático de los sucesos más importantes, centrándose en la guerra de Independencia. En el último volumen (v), relata la época de Iturbide, a quien veía como el verdadero autor de la independencia. En el penúltimo capítulo lleva a cabo un recuento de lo acontecido entre 1824 y 1852; el último capítulo, considerado como el "testamento político" de Alamán, presenta el programa de acción del Partido Conservador $^{21}$. Propone a Santa Anna como la única vía para imponer el proyecto conservador capaz de enderezar al país. En su planteamiento, recupera las experiencias tanto del pasado colonial como las de los años posteriores a la Independencia.

Su visión de la historia de México fue siempre la de una nostalgia del pasado colonial, cuyas instituciones habían sido destruidas por las improvisaciones y las disidencias políticas y sociales que surgieron a partir de la guerra de Independencia. En el momento en que empieza a escribir su Historia de México, justo después de la derrota frente a Estados Unidos, cuando ve a México empobrecido y en un estado de anarquía, Alamán busca encontrar las causas de ese presente. Si bien no cuestiona la Independencia en sí, sino que la acepta como un hecho consumado, duda de los beneficios que había aportado: condena el movimiento iniciado por Miguel Hidalgo en 1810 por haber eliminado a través de la violencia toda la herencia española y cuyo resultado fue dejar a la

21 Sin embargo, es la "Carta al General Santa Anna" la que mejor resume los principios del programa conservador: "Es el primero en conservar la religión católica [...] el único lazo común que liga a todos los mejicanos [...] también que es menester sostener el culto con esplendor y los bienes eclesiásticos [...]. Deseamos que el gobierno tenga la fuerza necesaria para cumplir con sus deberes, aunque sujeto a principios y responsabilidades que eviten los abusos [...]. Estamos contra la federación; contra el sistema representativo por el orden de elecciones que se ha seguido hasta ahora; contra los ayuntamientos electivos y contra todo lo que se llama elección popular [...]. Creemos necesaria una nueva división territorial, que confunda enteramente y haga olvidar la actual forma de Estado y facilite la buena administración, siendo éste el medio eficaz para que la federación no retoñe. Pensamos que debe haber una fuerza armada en número competente para las necesidades del país [...]. Estamos persuadidos que nada de esto puede hacer un Congreso y quisiéramos que U. lo hiciese ayudado por consejos, poco numerosos" (Alamán, 1997 [1853], pp. 351-352). nueva nación sumida en la anarquía. El segundo movimiento hacia la Independencia, encauzado por Agustín de Iturbide, parecía abrir un nuevo espacio de experiencia, en la medida en que el rompimiento de los lazos con España se llevaría a cabo como un "efecto natural" del transcurso de los siglos, pondría fin a las guerras civiles y sentaría las bases de un orden político estable.

Los liberales aceptaban la idea de que la independencia había sido un movimiento integral, iniciado por Hidalgo y completado por Iturbide, mientras que para Alamán no hubo una revolución, sino dos. Sin embargo, su posición es ambigua: aun cuando en algún momento parece defender a Iturbide, quien incluso aparece como el héroe de su Historia, tiene una opinión negativa sobre su Imperio, en parte por la "ridícula mascarada" de la coronación y los escandalosos adornos imperiales, pero sobre todo por los principios adoptados — en particular, la idea de la soberanía popular - que eran la causa de que continuara la anarquía que había comenzado en 1810. En otras palabras, Alamán no distingue tajantemente entre las revoluciones de Hidalgo e Iturbide. Su crítica se centra sobre todo en la improvisación política de la nueva clase gobernante y en la forma de gobierno llamada república.

\section{Historicismo: la escritura de la historia}

En sus primeros años, el conservadurismo y el historicismo estuvieron íntimamente relacionados. Karl Mannheim sostenía que, frente al racionalismo de los principios, el pensamiento conservador es pensamiento histórico. Lo que hace que el conservadurismo sea particularmente propenso a expresarse en términos históricos es que tiene una cierta inclinación hacia lo concreto, combinado con un gusto por lo que es, más que por lo que debería ser, es decir, valorando la experiencia histórica (cf. Armenteros, 2011). No en vano Alamán es el primer gran historiador mexicano. Se propone llevar a cabo una exploración sistemática de los hechos históricos: los hechos científicos, artísticos, técnicos, políticos o religiosos pueden considerarse hechos históricos porque tienen importancia para la vida del hombre. 
Criticando las ideas de la Ilustración en torno al orden político y la forma de gobierno, la experiencia de la historia era más fiable que el pensamiento abstracto. Al igual que de Maistre, para quien la historia era el vehículo de la Providencia, la premisa fundamental de la tesis conservadora defendida por Alamán es la visión providencialista de la historia, y uno de los usos de la historia es descubrir los designios de Dios. Alamán encuentra así un sentido intrínseco del proceso histórico:

Nosotros, guiados por las verdades de la fe cris-
tiana, debemos reconocer y adorar en todos los
sucesos humanos los decretos de la Providencia
divina, que por fines inescrutables a nuestra
limitada capacidad, deja en juego las pasiones de
los hombres hasta que le conviene contenerlas,
y desbaratando sus planes por los medios más
inopinados, sabe sacar bien del mal y todo lo
conduce por senderos que no podemos penetrar.
(1985, v, p. 955)

Como buen conservador, el valor que guiaba a Alamán era el del orden. En un discurso en la Cámara de Diputados en 1850 decía que se llamaban conservadores porque querían conservar la débil vida que el partido destructor le había dejado a México (González Navarro, 1985, p. xv). Por ello, al escribir su historia, al no poder encontrar el orden y la continuidad en los momentos de ruptura (la Conquista y la Independencia), los resultados de estos cambios atroces, junto con el desencanto frente al fracaso de las políticas liberales, se convierten en su espacio de experiencia, y cada uno de estos dos acontecimientos le proporciona los elementos para describir el presente y pensar en el futuro. En las Disertaciones considera que del nuevo orden que surge después de la Conquista proviene todo lo que somos: el idioma, la religión, las costumbres. La guerra de Independencia, por el contrario, destruyó todo ese orden social, dejó al país sumido en la anarquía, en la desilusión por el fracaso de proyectos y constituciones, gobiernos y reformas, la desesperanza que surgió frente al resultado terrible de la guerra contra Estados Unidos y la pobreza económica.
Siguiendo a Burke, para Alamán, si México quería progresar, tendría que basarse en sus tradiciones y evolucionar de manera lenta y gradual. Quería demostrarles a los mexicanos que el pasado continúa en el presente. Recupera el pasado, pero para ello elige el pasado que se inicia con la llegada de los españoles. No pretende regresar al pasado, sabe que no hay vuelta, la historia no es cíclica, no es el estudio de la prolongación de la existencia anterior en el presente. Somos el pasado en la forma de posibilidades reales que el pasado nos legó al perder su existencia de presente: rescata el pasado para el presente, pero el futuro para él no es una mera reedición de esas experiencias; no hay vuelta atrás. Alamán miraba hacia el futuro porque quería mantener los valores del presente, no era un reaccionario que trataba de volver a un pasado irrepetible y ya superado. Alamán rechazaba el supuesto de la repetición de la historia $\mathrm{y}$, por tanto, la idea de la historia magistra vitae: la Historia para él era un sistema y de lo que se trataba era de examinar los acontecimientos irrepetibles en sus relaciones recíprocas, para entender la lógica de su sucesión. Sabiendo que ese pasado ya no podía recuperarse para el presente, en menos de medio siglo México - dice en el último volumen de su Historia-

[...] ha cambiado su nombre, su extensión, sus habitantes en la parte influyente de su población, su forma de gobierno, sus usos y costumbres, y esto no solo por las grandes revoluciones que en ella hemos visto atropellarse unas en pos de otras, sino también por efecto del cambio completo que todo ha experimentado en el mundo en la misma época. (1985, v, pp. 871-872)

$\mathrm{Y}$ puesto que los hechos históricos no se repiten, no es posible extraer lecciones morales de ese pasado colonial que pudieran aplicarse a toda época histórica, sino como él mismo afirma:

[...] mi principal atención ha sido, considerando el conjunto de los sucesos, desde los primeros movimientos del año 1808 hasta la época en que escribo, demarcar bien las ideas que se presentaron desde el principio, como base y medios de la revolución y seguirlas en todo su progreso, hacer notar el influjo que tuvo sobre la moralidad 
Universidad Pedagógica Nacional

Facultad de Humanidades

de la masa de la población el primer impulso que a aquella se dio, y las consecuencias que ha producido el pretender cambiar no solo el estado político, sino también el civil. (1985, I, p. XI)

Si bien no enfatiza la repetición de lo ejemplar, ni, como decíamos, la historia es para él magistra vitae, su obra sí tiene un propósito didáctico: formar a las futuras generaciones para que no cometan los mismos errores que la suya. Para él, la utilidad de la historia radica

[...] no precisamente en el conocimiento de los hechos, sino en penetrar el influjo que éstos han tenido los unos sobre los otros; en ligarlos entre sí de manera que en los primeros se eche de ver la causa productora de los últimos, y en esos la consecuencia precisa de aquellos con el fin de guiarse en lo sucesivo por la experiencia del pasado. (1985, I, p. XI)

En la introducción del tomo $\mathrm{v}$ de su Historia nos dice:

Ofrece esta [segunda parte de su historia] por lo mismo mayor interés que la primera, no solo por ser más recientes los sucesos que en ella se refieren sino por la conexión que tienen con los presentes, que reconocen en aquellos su origen y principio. (1985, v, p. 9)

\section{Los usos políticos del pasado historiográfico}

Durante la segunda parte del siglo xIx, los usos políticos del pasado se vieron reflejados en otros fines y objetivos de la historiografía. Mientras que después de la Independencia se trataba de elaborar un discurso integrador, a partir de 1848, después de la experiencia de la guerra con Estados Unidos, se llevó a cabo una seria reflexión acerca de la realidad mexicana, subrayando la falta de cohesión nacional: algunos historiadores se preguntaron si realmente se podía hablar de la existencia de una nación. En 1843, la Constitución Política denominada Las bases orgánicas, sentaba las "bases generales" que debían regir todos los "estudios preparatorios". Se intentaba por primera vez en el México independiente el estudio de la historia como parte importante en la formación intelectual y moral de los alumnos. La historia, junto con la lectura y el análisis crítico de los clásicos parecería suplir una carencia: la falta de conciencia histórica que tanto echó de manos Humboldt entre los jóvenes criollos (Ortega \& Medina, 1970, p. 75). Con el decreto del estudio de la historia, los distintos historiadores al frente de las cátedras iniciaron la primera polémica historiográfica sobre el concepto de historia, los métodos y los valores que debían de inspirar la investigación historiográfica ${ }^{22}$.

En ese momento de crisis, entre la esperanza de tiempos nuevos y las certezas del pasado, surgió la necesidad de iniciar una reflexión sobre la situación del país, buscando las causas de los antagonismos de esa lamentable realidad. La obra de Lucas Alamán se inscribe dentro de esa recuperación del pasado, pero a diferencia de los otros autores que buscan escribir la historia de México, su obra revela una nueva concepción del tiempo y la historia. Sentando las bases de una nueva forma de historiografía, puso el acento en la explicación y en el uso de todo tipo de documentos que comprueben su historia: "La fuerza de su argumento - dice Hale — se basaba no en mera polémica, sino en la documentación y el detalle de sus cinco amplios volúmenes" 23 . No se limitaba a presentar los acontecimientos en su orden cronológico, sino que propuso una manera de relacionarlos, de entender la historia como proceso y no como una serie de hechos aislados. Buscaba ser objetivo (aunque no lo lograra en realidad): “Omitiré en cuanto lo permita la materia, toda observación propia, dejando que el lector ejerciendo su juicio, califique por sí mismo el mérito de cada acción, cuando esté instruido a fondo de su esencia” (Alamán, 1985, v, p. 67). Su punto de partida era el presente — "las cosas tales como fueron"- en nombre del futuro. $\mathrm{Su}$ actitud ante el cambio también lo distinguía de los reaccionarios: no era hostil hacia toda reforma,

22 Un ejemplo es la polémica que se dio entre José Gómez de la Cortina y José María Lacunza en el diario El Siglo XIX.

23 Y continua Hale: "Su Historia de Méjico sigue siendo el tratamiento patrón del periodo 1810-1821 y nunca se ha igualado por una versión 'liberal'” (2005, p. 22). 
sino que estaba dispuesto a realizar las que fueran necesarias para conservar los valores del pasado:

Por conclusión, puedo asegurar, que los motivos que me han guiado en la redacción de esta obra, no han sido otros que presentar a mis lectores y a la posteridad las cosas tales como fueron, para que el conocimiento exacto de lo pasado y lo presente, sirva de lección para lo futuro, [...]. (Alamán, 1985, V, p. 10)

En palabras de Fernández Sebastián, en

[...] las últimas décadas del siglo xvini y en las primeras del XIX, coincidiendo con las reformas ilustradas y, sobre todo, con las llamadas revoluciones liberales y de independencia, se produjo en el Atlántico hispano-luso una mutación profunda en el universo léxico-semántico que vertebraba las instituciones y las prácticas políticas. [...] ese gran terremoto político-conceptual, un vasto seísmo con varios epicentros que alcanzó a buena parte del mundo occidental, fue acompañado en muchos lugares de un cambio en la vivencia del tiempo y de una conciencia más aguda de la historicidad de las sociedades. (2009, p. 28)

La búsqueda de la verdad de los hechos era el objetivo fundamental de Alamán al escribir su Historia de México, lo que lo condujo a evaluar los acontecimientos que formaron las experiencias de los actores individuales y colectivos. Alamán afirmaba: "México es una nación en [la] que todo está por hacerse, por haberse destruido todo lo que existía” (1985, v, p. 14). Su tarea era recuperar esas experiencias, recordándolas, incorporándolas, evitando que desaparecieran de nuestro presente, para que pudieran ser reconocidas $y$, a partir de ese pasado hecho presente, saber qué sucedió. Toda vida humana, sostiene Koselleck,

[...] está constituida por experiencias, bien sean estas nuevas y sorprendentes o, por el contrario, de naturaleza repetitiva. Se necesitan conceptos para poder tener o acumular experiencias e incorporarlas vitalmente. Son necesarios para fijar las experiencias, que se diluyen, para saber qué sucedió y para conservar el pasado en nuestro lenguaje. (2012, p. 29)
Las experiencias históricas que recuperó Alamán se concentraban en "la ruptura del orden tradicional": fueron trescientos años de experiencia histórica, que se extinguió con la guerra de Independencia y privó de validez los prejuicios y las tradiciones, y precipitó a México en el caos, en la anarquía, en una situación en la que todo estaba por hacerse.

Alamán recuperó el pasado y mirando hacia el futuro, construyó nuevas expectativas que buscaban abrir un camino provechoso para la nación. La distancia entre pasado y futuro dio lugar a una nueva articulación entre presente, pasado y futuro; este paso a un nuevo régimen de temporalidad implicó un cambio en las formas de pensar y de escribir la historia.

Tras la derrota del Imperio de Maximiliano, la reconstrucción nacional que se proponía el partido liberal tuvo grandes repercusiones en la historiografía. Una ley decretó como obligatoria la enseñanza de la historia de México, con la idea de que era una buena vía para consolidar el sentimiento nacional. De la separación entre Iglesia y Estado surgió la idea de que se necesitaba un nuevo sustento ideológico y este lo podía proporcionar nada menos que la historia: había que crear un nuevo carácter nacional, laico, que modificara las costumbres, los hábitos mentales y aun los valores de los mexicanos. Aparecieron relatos históricos, moralizantes y edificantes para la juventud, que asumieron el papel que antes habían desempeñado las enseñanzas religiosas. Mediante una historia patria los educandos conocerían su herencia y reverenciarían a sus héroes, quienes asumirían así el lugar del santoral.

Hacia finales de siglo, los debates giraban en torno a los proyectos para elaborar una historia general de México. Esta empresa, cuyo objetivo era escribir cuanto antes una historia general, fue iniciada por el tratado de Manuel Larrainzar Algunas ideas sobre la historia y manera de escribir de México, especialmente la contemporánea, desde la Declaración de Independencia, en 1821, hasta nuestros días. Dicha historia tenía que ser una obra de conjunto, estructurada sobre el esquema 
Universidad Pedagógica Nacional

Facultad de Humanidades

tripartito: Historia antigua (prehispánica), Historia media (desde la Conquista hasta la Independencia) e Historia moderna (desde la Independencia hasta la época en que vivía Larrainzar), aprovechando la existencia de obras impresas, crónicas, monografías, documentos varios. Tras la derrota de los conservadores, la tarea fue retomada por los victoriosos liberales, quienes años más tarde, dirigidos por Riva Palacio, redactaron y publicaron México a través de los siglos, que se convirtió en la "historia oficial” de México ( $c f$. Ortega \& Medina, 1970).

En la construcción de la historia nacional, que empezó a convertirse en un mito político unificador, encontramos ideologías encontradas, pero también un motivo común: crear una conciencia nacional. La presencia de esas ideologías es clara en las concepciones de la historia, en las ideas y conceptos presentes en las obras historiográficas (progreso, objetividad, verdad, método). Historias generales de México y libros de texto logran construir una visión oficial de nuestra historia, en la que son patentes los usos políticos del pasado.

\section{Referencias bibliográficas}

Alamán, L. (1942). Disertaciones sobre la historia de la República Mexicana desde la época de la conquista que los españoles hicieron a fines del siglo $\mathrm{xV}$ y principios del XVI de las islas y continente americano hasta la Independencia (1844-1849), México: Jus.

Alamán, L. (1985). Historia de México desde los primeros movimientos que prepararon su independencia en el año de 1808 hasta la época presente, 5 vols., México: FCE-Instituto Cultural Helénico. [Edición facsimilar de 1850, Historia de Méjico desde los primeros movimientos que prepararon su independencia en el año de 1808 hasta la época presente, tomos I-V México, Mariano Lara].

Alamán, L. (1997) [1853], Carta a Antonio López de Santa Anna. En A. Lira (selección y prólogo). Lucas Alamán. México: Cal y Arena, Col. Los Imprescindibles.

Armenteros, C. (2011). The French idea of history. Joseph de Maistre and his heirs, 1794-1854. Ithaca y Londres: Cornell University Press.

Bustamante, C. M. (1985). Cuadro histórico de la Revolución mexicana de 1810, 8 vols. México:
Instituto Cultural Helénico, FCE. [Facsímil de: Cuadro histórico de la Revolución mexicana. México: Imprenta a cargo de J. Mariano Lara, 1842-1844, 1846].

Cano, A.; Suárez Cortina, M. \& Trejo Estrada, E. (eds.) (2010). Cultura liberal, México y España, 1860-1930. México/Santander: Universidad Nacional Autónoma de México y Universidad de Cantabria.

Chevalier, F. (1999). América Latina. De la Independencia a nuestros días. México: FCE.

Chiaramonte, J. C. (2004). Nación y Estado en Iberoamérica. El lenguaje político en tiempos de las independencias. Buenos Aires: Sudamericana.

Fernández Sebastián, J. (Dir.) (2009). Diccionario político $y$ social del mundo moderno iberoamericano. La era de las revoluciones, 1750-1850. (Iberconceptos-I). Madrid: Fundación Carolina, Sociedad Estatal de Conmemoraciones Culturales, Centro de Estudios Políticos y Constitucionales.

Fowler, W. \& Morales Moreno, H. (coords.) (1999). El conservadurismo mexicano en el siglo XIX. Puebla: Benemérita Universidad Autónoma de Puebla, Saint Andrews University, Scotland, U. K., Secretaría de Cultura, Gobierno del Estado de Puebla.

González Navarro, M. (1952). El pensamiento político de Lucas Alamán. México: El Colegio de México.

González Navarro, M. (1985). Alamán historiador. En L. Alamán (1985), t. 1, pp. XI-XXIII.

Hale, A. C. (2005). El liberalismo en la época de Mora. México: Siglo XxI.

Hale, A. C. (2008). Emilio Rabasa and the survival of Porfirian liberalism. The man, his career, and his ideas, 1856-1930. Chicago: Stanford University Press.

Hartog, F. (2003). Régimes d'historicité. Présentisme et expériences du temps. París: Seuil. ["Órdenes del tiempo, regímenes de historicidad”, en Historia y Grafía, 21, pp. 73-101].

Hobsbawm, E. (1994). The nation as invented tradition. En J. Hutchinson y A. D. Smith (eds.). Nationalism. Oxford Readers, Oxford/Nueva York: Oxford University Press.

Kirk, R. (1953). The conservative mind: From Burke to Eliot. Ann Arbor Michigan: University of Michigan Library.

Koselleck, R. (1993). Futuro pasado: para una semántica de los tiempos históricos. Barcelona: Paidós. 
Koselleck, R. (2012). Historias de conceptos. Estudios sobre semántica y pragmática del lenguaje político social. Madrid: Trotta.

Landavazo, M. A. \& Sánchez, A. A. (coords.) (2008). Experiencias republicanas y monárquicas en México, América Latina y España, siglos XIX y Xx. Michoacán: Universidad Michoacana de San Nicolás de Hidalgo.

Lefebvre, G. (1974). El nacimiento de la historiografía. Barcelona: Martínez Roca.

Linares, Ó. (2012). El color de la "nación". Tesis de Maestría en Estudios Latinoamericanos. México: UNAM.

Lira, A. (1984). Espejo de discordias. La sociedad mexicana vista por Lorenzo de Zavala, José María Luis Mora y Lucas Alamán. México: SEP.

Mier Noriega \& Guerra, J. S. de (1986). Historia de la revolución de la Nueva España antiguamente Anáhuac, 2 vols. México: Instituto Cultural Helénico, FCE, 1986. [Facsímil de Historia de la revolución de Nueva España, antiguamente llamada Anáhuac o, verdadero origen y causas de ella con la relación de sus progresos hasta el presente año de 1813. Londres, Imprenta de Guillermo Glindson, 1813].

Mijangos, P. (2004). El pensamiento religioso de Lucas Alamán. Estudios. Historia, Filosofía, Letras, 68, pp. 55-78.

Mora, J. M. L. (1965). México y sus revoluciones. México: Porrúa.

Noriega, A. (1972). El pensamiento conservador y el conservadurismo mexicano. 2 vols., México: IIJ-UNAM.

O'Gorman, E. (1999). México. El trauma de su historia. Ducit amor patriae. México: Conaculta.
Ortega y Medina, J. A. (1970). Polémicas y ensayos mexicanos en torno a la historia. [Notas bibliográficas e índice onomástico por Eugenia Meyer.] México: UNAM.

Ortega y Medina J. A. \& Camelo, R. (coord. gral.) (2011). El surgimiento de la historiografía nacional, vol. III, coord. Virginia Guedea. México: UnAm.

Pani, E. (2009). Las fuerzas oscuras. El problema del conservadurismo en la historia de México. En E. Pani (coord.) Conservadurismo y derechas en la historia de México (pp. 11-42). México: FCE-Conaculta.

Rosanvallon, P. (1985). Le moment Guizot, París: Gallimard.

Suárez Cortina, M. (2013). Federalismo, religión y política en el siglo XIX: España y México en perspectiva comparada. En M. Suárez, E. Trejo Estrada \& A. Cano Andaluz (eds.) (2013). Cuestión religiosa. España y México en la época liberal. Santander: Universidad de Cantabria.

Tornel y Mendivil, J. M. (1985) [1852]. Breve reseña histórica de los acontecimientos más notables de la nación mexicana. México: Instituto Nacional de Estudios Históricos de la Revolución Mexicana.

Wobeser, G. von. (coord.) (2010). Historia de México, México: Presidencia de la República-SeP- FCEAcademia Mexicana de Historia.

Zavala, L. (1985). Ensayo histórico de las revoluciones de México de 1808 a 1830. México: Instituto Cultural Helénico-FCE.

Zermeño. G. (2003). Imparcialidad, objetividad y exactitud. Valores epistémicos en el origen de la historiografía moderna en México. Historia y Grafía, 20, 49-83. 